\title{
Foliage Attributes for Current-year Shoots of Fraser Fir
}

\author{
J.F. Brewer ${ }^{1}$, L.E. Hinesley ${ }^{2}$, and L.K. Snelling ${ }^{3}$ \\ Department of Horticultural Science, North Carolina State University, \\ Raleigh, NC 27695-7609
}

Additional index words. Abies fraseri, Christmas trees, specific area, needle area, foliage weight, needle weight, leaf area index

\begin{abstract}
Current-year shoots of Fraser fir [Abies fraseri (Pursh) Poir.] were sampled in Christmas tree plantations in western North Carolina. Needles were sampled at five positions on each shoot: $0 \%$ (proximal end), $25 \%, 50 \%, 75 \%$, and $100 \%$ (distal end). At each position, needles were collected in a tight left-hand spiral beginning on the abaxial side (bottom) and ending on the adaxial side (top). Length, width, thickness, dry weight, and projected surface area were determined for each needle. Specific area (one-sided) averaged $45 \mathrm{~cm}^{2} \cdot \mathrm{g}^{-1}$ and increased from the shoot base to the tip. On individual shoots, needle dimensions were maximal at the middle $(50 \%$ position). Within sample positions, needle dimensions increased from the adaxial to the abaxial side. Needle length, weight, and area differed more than width or thickness by position. Needle surface area per centimeter of shoot was relatively stable. Regression models using shoot length, diameter, needle density, and average needle length or weight yielded good estimates of total foliage area and weight.
\end{abstract}

Fraser fir is a valuable ornamental and Christmas tree species indigenous to the higher mountains of eastern Tennessee, western North Carolina, and southwestern Virginia. It is closely related to balsam fir [Abies bulsamea (L.) Mill.], a more northern species

Received for publication 6 Mar. 1992. Accepted for publication 18 Mar. 1992. This research was funded by the North Carolina Agricultural Research Service (NCARS), Raleigh, NC 276957643. We thank J.F. Walgenbach, S.L. Warren, F.A. Blazich, and D.M. Pharr for use of their laboratories and equipment. Use of trade names does not imply endorsement by the NCARS, nor criticism of similar products not mentioned. The cost of publishing this paper was defrayed in part by the payment of page charges. Under postal regulations, this paper therefore must be hereby marked advertisement solely to indicate this fact.

'Graduate Research Assistant.

${ }^{2}$ Professor

${ }^{3}$ Research Technician.
(Robinson and Thor, 1969). Fraser fir has a natural Christmas tree shape and needs minimal shearing. It has glossy, dark-green foliage, excellent needle retention, strong branches, and a pleasant aroma (Bailian et al., 1988). Use of Fraser fir as a Christmas tree is expanding nationally, creating the need for more information concerning its nutrition, physiology, growth, and management.

The capability to estimate foliage surface area is useful in problems involving watershed management, growth, nutrition, photosynthesis, and transpiration (Loomis et al., 1966). Because this information was lacking for Fraser fir, our objectives were to characterize surface area, length, width, thickness, weight, and density of foliage on current-year shoots of Fraser fir, and to develop regression models to estimate total surface area and dry weight for foliage on current-year shoots.

Fraser fir Christmas trees $(\approx 2 \mathrm{~m}$ in height $)$ 

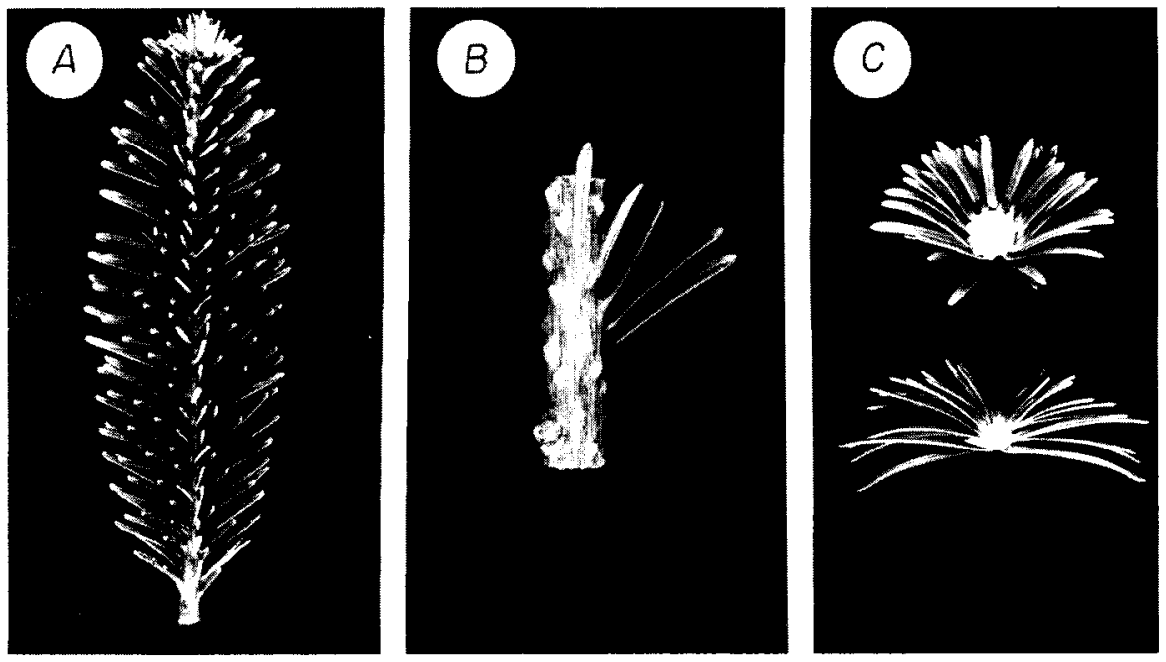

Fig. 1. Needle and foliage traits of current-year shoots of Fraser fir. (A) Adazial view; sampling positions: $0 \%$ (base), $25 \%, 50 \%, 75 \%$, and $100 \%$ (tip). (B) Tight, left-hand spiral with needle size increasing from adaxial (top) to abaxial (bottom) side. (C) Distal view of shoot grown in full sun and upper crown (top), compared to shaded branch from lower crown (bottom).
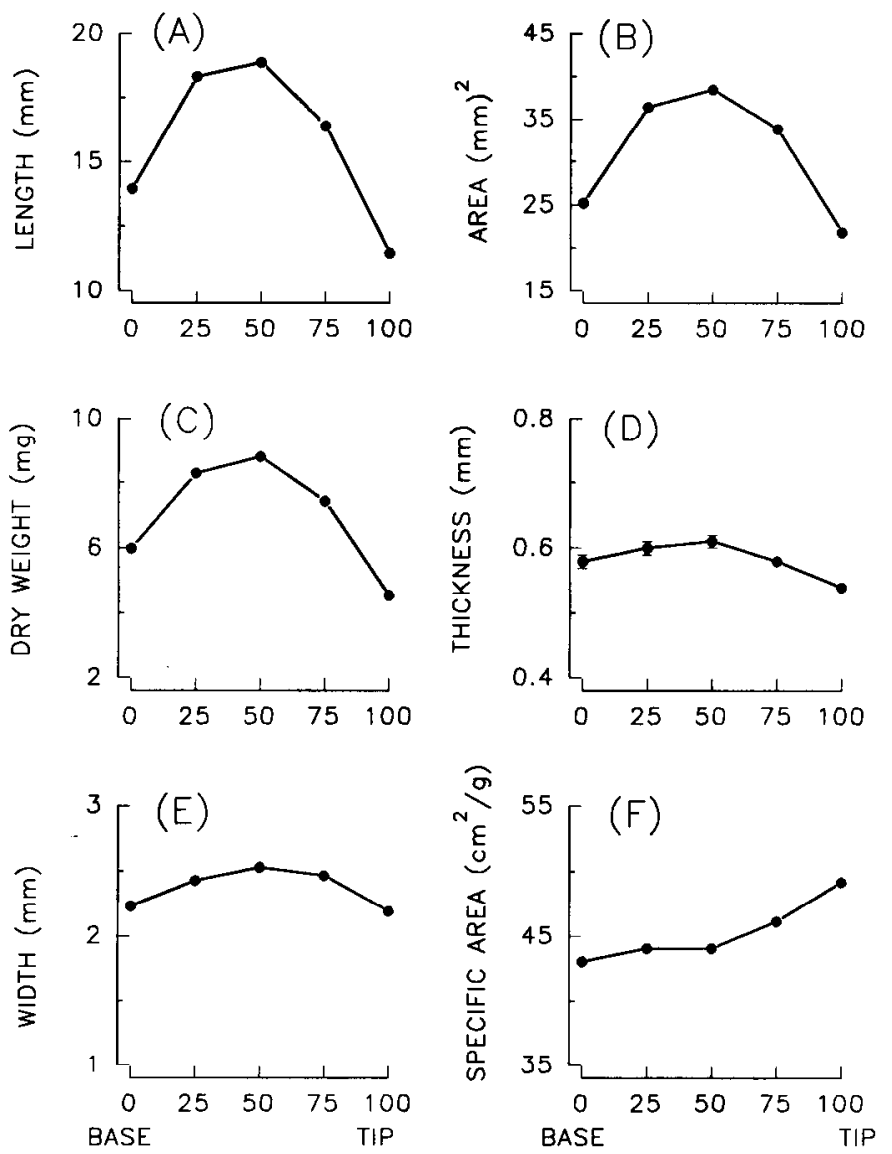

POSITION ON SHOOT

Fig. 2. Relationship of sampling position on a shoot to various needle traits: (A) length, (B) surface area (one-sided), (C) dry weight, (D) thickness, (E) width, and (F) specific area. Basis $=162$ current-year shoots. Means include all needles sampled at a particular position. No SE bars are shown because all were smaller than symbols.

were sampled in Nov. 1989 from five plantations in four western North Carolina counties: 1) Ashe (elevation $914 \mathrm{~m}), 2$ ) Allegheny (1080 m), 3) Haywood (810 m), and 4) Av- ery $(980 \mathrm{~m})$. Trees were of open pollinated origin, either from Roan Mt. (lat. $36^{\circ} 10^{\prime} \mathrm{N}$, long. $82^{\circ} 10^{\prime} \mathrm{W}$ ) or Mt. Rogers (lat. $36^{\circ} 40^{\prime} \mathrm{N}$, long. $\left.81^{\circ} 30^{\prime} \mathrm{W}\right)$. Use of several plantations provided trees from a variety of sites and management practices, yielding a good range of shoot and needle attributes for this species. Within Fraser fir, which has a very restricted natural range, variation in foliage attributes is much greater among individual trees than between stands or populations (Robinson and Thor, 1969).

Nonsheared, current-year shoots were collected from 15 to 20 trees in each plantation. Trees were sampled that maximized variation in needle morphology and density. Shoots were selected throughout the crown, excluding leaders, and each shoot was severed at its insertion point. Shoots were transported on ice to Raleigh and stored at $4 \mathrm{C}$ pending analysis. Shoots from each plantation were grouped according to length: small (4 to 13 $\mathrm{cm})$, medium $(13.5$ to $24 \mathrm{~cm})$, and large $(24.5$ to $42 \mathrm{~cm})$. Ten to 12 shoots were retained from each group for foliage measurements.

Shoot length (centimeters) was measured from the base to the tip of the terminal bud. Shoot diameter (millimeters) was measured with calipers-two measurements perpendicular to each other-halfway between the proximal and distal ends (50\% position). Needles were counted on a $2-\mathrm{cm}$ segment at the $50 \%$ position.

Needles were collected from five positions on each shoot: $0 \%$ (base), $25 \%, 50 \%, 75 \%$, $100 \%$ (distal end) (Fig. 1A). At each position, beginning on the abaxial side, needles were removed from a tight, left-hand spiral (Chandler and Dale, 1990) that ended on the adaxial side (Fig. 1B). Sampling in the $100 \%$ position excluded very small needles subtending the terminal and subterminal buds, and sampling in the $0 \%$ position excluded the lowest spiral. On small shoots $(\leq 8 \mathrm{~cm}$ long), if the spiral in one sampling position overlapped an adjacent sampling position, needles were collected in an arc perpendicular to the shoot axis, and the number of sampling positions was reduced to $0 \%, 50 \%$, and $100 \%$.

Needles were taped to white paper (one page per shoot), photocopied, and stored in a closed container at $4 \mathrm{C}$ pending further analysis. The identity of each needle was maintained relative to sampling position and location within the spiral. After sampling from each position, shoots were dried to constant weight at $70 \mathrm{C}$, and residual foliage was removed and weighed.

Each needle was cross sectioned at its midpoint and thickness measured under a dissecting microscope. Subsequently, needles were dried at $70 \mathrm{C}$ for $24 \mathrm{~h}$ and weighed individually. Needle lengths, widths, and areas were measured from the photocopies using a Monochrome Agvision System area meter (Decagon Devices, Pullman, Wash.) with DIAS II software (version 1.0, ca. 1989). To compute one-sided area, a correction factor was applied to account for the elliptical upper surface of needles (Drew and Running, 1973; Gholz et al., 1976). The correction $(\mathrm{C})$ was $\mathrm{C}=\left(\pi / 2 \sqrt{ } /\left(\mathrm{W}^{2}+\mathrm{T}^{2}\right) / 2\right) / \mathrm{W}$, where $\mathrm{W}=$ needle width (millimeters) and $\mathrm{T}=$ needle thickness (millimeters). Based on an average needle width : thickness ratio 
NEEDLE TRAITS
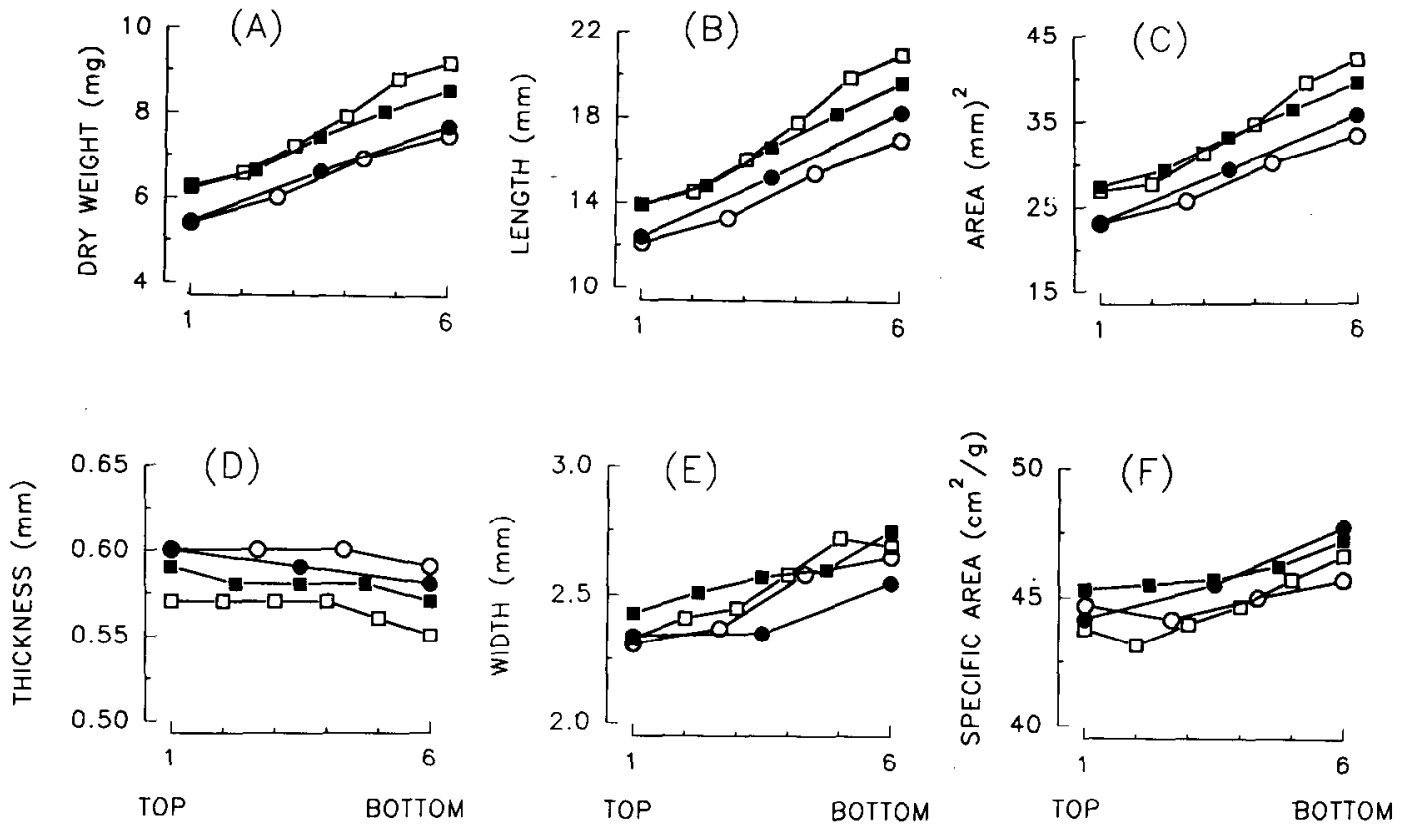

POSITION ON SPIRAL

Fig. 3. Relationship of various needle traits (location on shoot equals $50 \%$ position) to position on a spiral: (A) dry weight, (B) length (C) surface area (one-sided), (D) thickness, (E) width, and (F) specific area. Basis = 162 current-year shoots. Each point is the mean for all shoots with a certain number of needles in the spiral: three $(\bullet)$, four ( $O$ ), five ( $\square)$, or six $(\square)$.

\section{NEEDLE TRAITS}
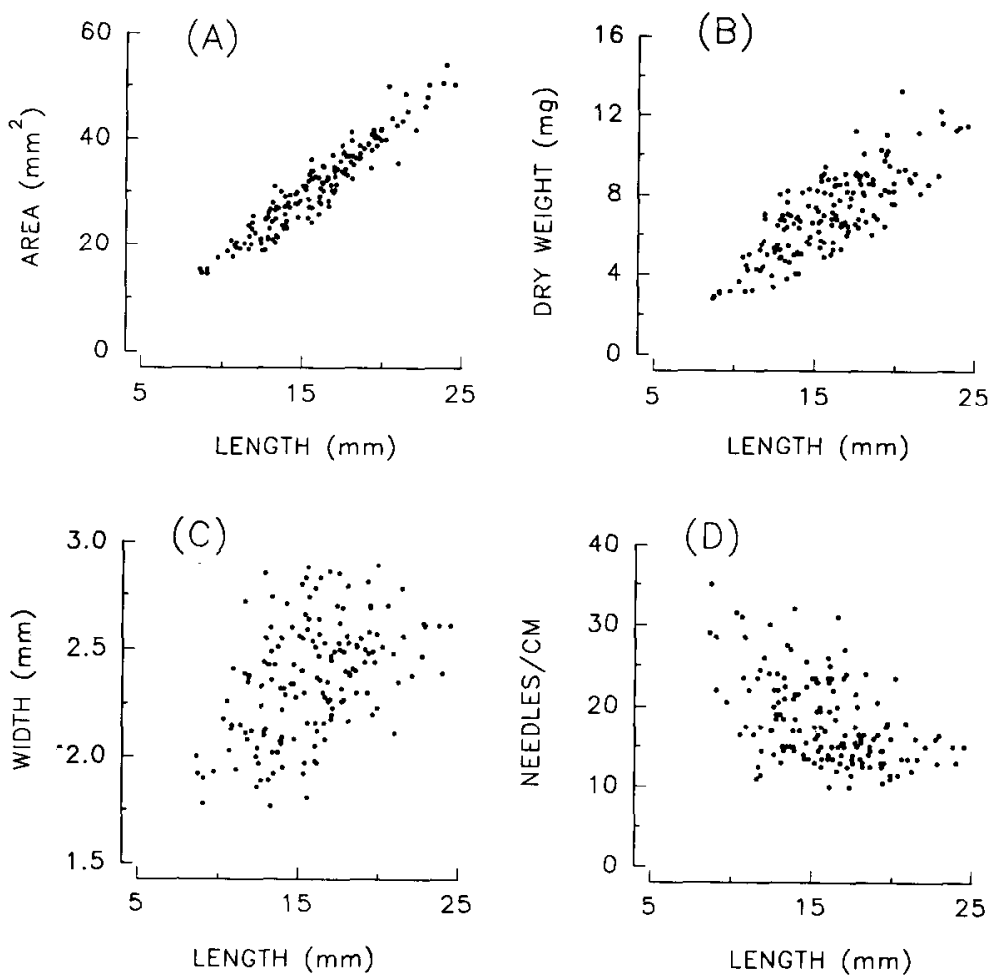

Fig. 4. Relationship between needle length $\left(\mathrm{L}_{\mathrm{N}}\right.$, millimeters) of Fraser fir and other needle traits. (A) Surface area $\left(\mathrm{A}_{\mathrm{N}}\right.$, square millimeters, one-sided); model: $\ln \left(\mathrm{A}_{\mathrm{v}}\right)=0.0248+1.2 .302 \ln \left(\mathrm{L}_{\mathrm{N}}\right)$ $\left(R^{2}=0.90 ; \mathrm{s}_{y \cdot x}=0.087\right)$. (B) Dry weight $\left(\mathrm{WT}_{\mathrm{N}} ;\right.$ milligrams $)$; model: $\ln \left(\mathrm{WT}_{\mathrm{N}}\right)=-1.4462+$ $1.22301 \ln \left(\mathrm{L}_{\mathrm{N}}\right)\left(R^{2}=0.68 ; \mathrm{s}_{\mathrm{y} \cdot \mathrm{x}}=0.184\right)$. (C) Width $(\mathrm{W} ;$ millimeters $)$; model: $\ln (\mathrm{W})=0.0840$ $+0.2812 \ln \left(\mathrm{L}_{\mathrm{N}}\right)\left(R^{2}=0.27 ; \mathrm{s}_{\mathrm{y} \cdot \mathrm{x}}=0.102\right)$. (D) Needle density (DEN, needles per centimeter); model: $\ln (\mathrm{DEN})=4.5318-0.6130 \ln \left(\mathrm{L}_{\mathrm{N}}\right)\left(R^{2}=0.23 ; \mathrm{s}_{\mathrm{y} \cdot \mathrm{x}}=0.241\right)$. Basis $=162$ current-year shoots. Each point is a mean for all needles sampled on that shoot. In = natural logarithm. All models were significant $(P=0.01) ; \mathrm{s}_{y \cdot \mathrm{x}}=\mathrm{SE}$ of regression. of $4: 1$, the mean value of $C$ was 1.145 .

For each shoot, specific area (square centimeters per gram; one-sided) was calculated as $\left(\mathrm{AN} / \mathrm{WT}_{\mathrm{N}}\right) \times 10$, where $\mathrm{A}_{\mathrm{v}}=$ average needle area in square millimeters (based on all sample needles from that shoot) divided by average needle dry weight in milligrams $\left(\mathrm{WT}_{\mathrm{N}}\right)$. Total foliage area was estimated as specific area $\times$ total foliage dry weight in grams. Mean needle length, area, weight, thickness, width, and specific area were also calculated for each sample position (Fig. 2), as well as for needles within the spiral at the $50 \%$ position (Fig. 3). Means in Fig. 3 were plotted according to the number of needles in the spiral at the $50 \%$ position. The range, mean, and SE, respectively, for each characteristic was as follows: shoot length (4.5 to $42 \mathrm{~cm}, 19.4,0.72$ ); average needle length ( 8.7 to $25.5 \mathrm{~mm}, 15.9,0.26)$; average needle dry weight (2.8 to $13.6 \mathrm{mg}, 7.1,0.17)$; needle density (10 to 35 needles per $\mathrm{cm}, 18,0.41$ ); and needle width (1.8 to $3.1 \mathrm{~mm}, 2.4,0.02)$.

Standard errors were calculated or data were evaluated with regression as appropriate (SAS Institute, 1989). Logarithmic and square root transformations were used, if needed, to normalize variance and/or linearize the relationships. Only the better relationships $\left(R^{2} \geq\right.$ 0.15 ) are shown in figures.

The terms foliage and needle refer to attributes of shoots and individual needles, respectively. Unless stated otherwise, estimates of surface area are for one side.

Needle length (Fig. 2A), area (Fig. 2B), and dry weight (Fig. 2C) followed a parabolic curve from the base to the tip of the shoot, having a maximum at the $50 \%$ position. Needle thickness (Fig. 2D) and width 

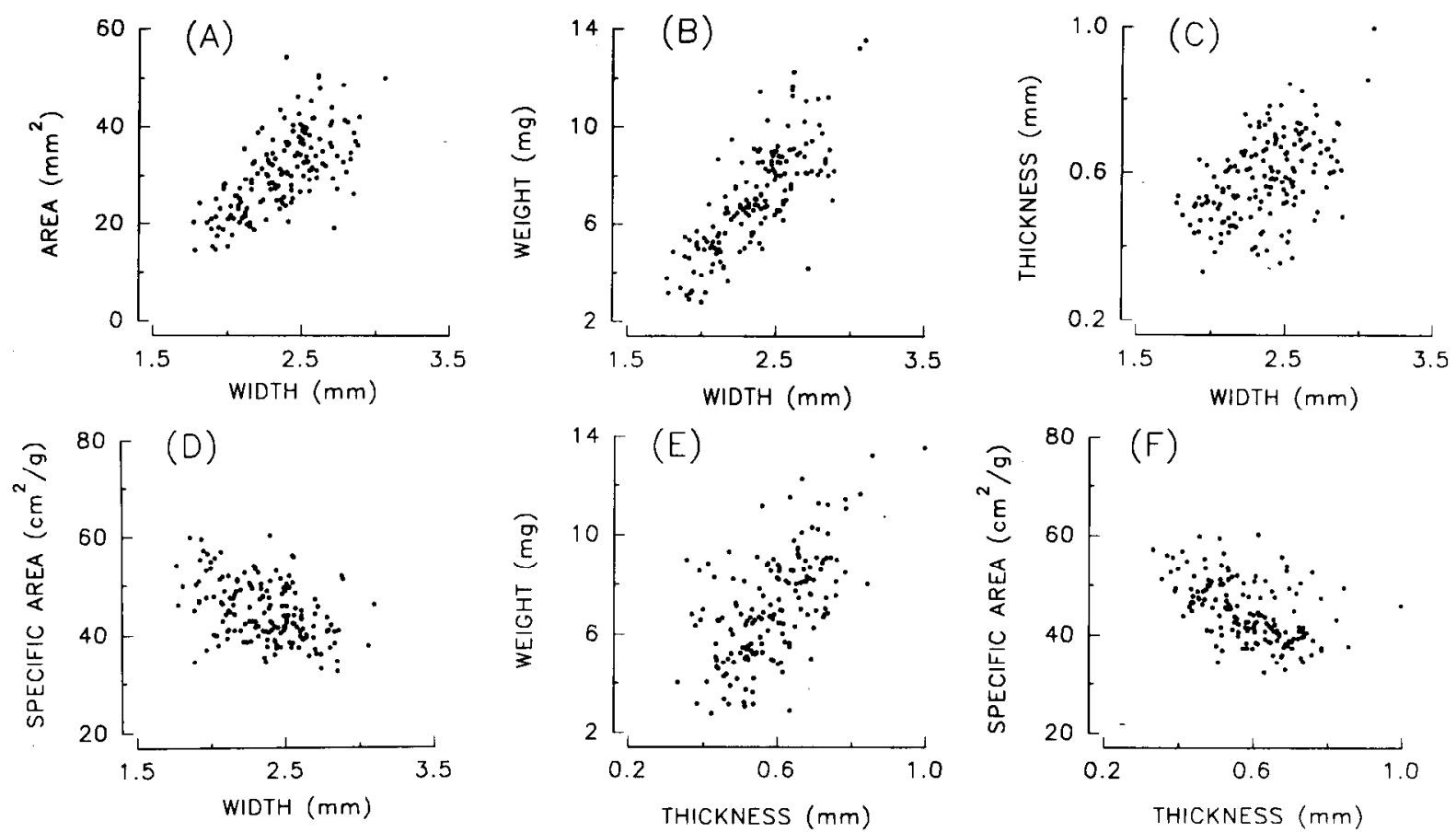

Fig. 5. Relationship between needle width (W, millimeters) and thickness (T, millimeters) of Fraser fir needles and other needle traits. (A) Surface area $\left(\mathrm{A}_{\mathrm{N}}\right.$, square millimeters one-sided) vs. width; model: $\ln \left(\mathrm{A}_{\mathrm{N}}\right)=1.9505+1.6934 \ln (\mathrm{W})\left(R^{2}=0.51 ; \mathrm{s}_{\mathrm{y} \cdot \mathrm{x}}=0.197\right)$. (B) Dry weight (WT $\mathrm{W}$, milligrams) vs. width; model: $\ln (\mathrm{WT})=0.0643+2.15601 \ln (\mathrm{W})\left(R^{2}=0.62 ; \mathrm{s}_{\mathrm{y} \cdot \mathrm{x}}=0.198\right)$. (C) Thickness vs. width; model: $\ln (\mathrm{T})=-1.2252+0.7883 \ln (\mathrm{W})$ $\left(R^{2}=0.22 ; \mathrm{s}_{\mathrm{y}} \cdot \mathrm{x}=0.174\right)$. (D) Specific area $\left(\mathrm{SA}\right.$, square centimeters per gram) vs. width; model: $\ln (\mathrm{SA})=4.1888-0.46262 \ln (\mathrm{W})\left(R^{2}=0.17\right.$; $\left.\mathrm{s}_{\mathrm{y} \cdot \mathrm{x}}=0.123\right)$. (E) Dry weight vs. thickness; model: $\mathrm{WT}_{\mathrm{N}}=7.45-13.01(\mathrm{~T})+20.30\left(\mathrm{~T}^{2}\right)\left(R^{2}=0.39 ; \mathrm{s}_{\mathrm{y} \cdot \mathrm{x}}=1.68\right)$. (F) Specific area vs. thickness; model: $\ln (\mathrm{SA})=3.6019-0.3472 \ln (\mathrm{T})\left(R^{2}=0.26 ; \mathrm{s}_{\mathrm{y} \cdot \mathrm{x}}=0.116\right)$. Basis $=162$ current-year shoots. Each point is the mean for all needles sampled on that shoot. $l n=$ natural logarithm. All models were significant $(P=0.01) ; \mathrm{s}_{\mathrm{y} \cdot \mathrm{x}}=\mathrm{SE}$ of regression.

SHOOT TRAITS
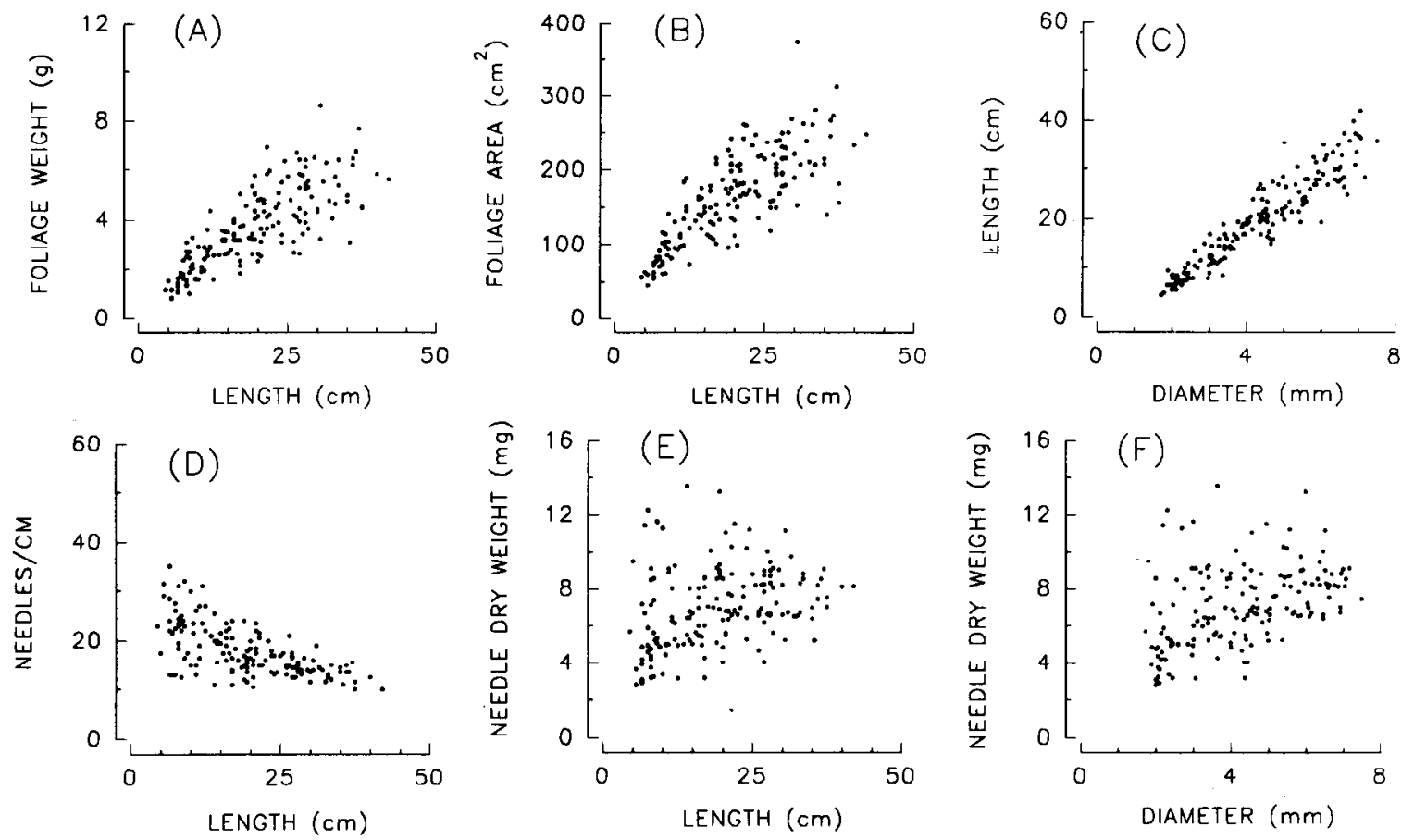

Fig. 6. Relationship between shoot and needle traits of Fraser fir. (A) Total foliage dry weight $\left(\mathrm{WT}_{\mathrm{F}}\right.$, grams) vs. shoot length ( $\mathrm{L}_{\mathbf{S}}$, centimeters); model: $\ln \left(\mathrm{WT}_{\mathrm{F}}\right)=-0.9693+0.7664 \ln \left(\mathrm{L}_{\mathrm{S}}\right)\left(R^{2}=0.72 ; \mathrm{s}_{\mathrm{y}} \cdot \mathrm{x}=0.257\right)$. (B) Total foliage area ( $\mathrm{A}_{\mathrm{F}}$, one-sided, square centimeters) vs. shoot length; model: $\ln \left(\mathrm{A}_{\mathrm{F}}\right)=3.0088+0.7012 \ln \left(\mathrm{L}_{\mathrm{s}}\right)\left(R^{2}=0.74 ; \mathrm{s}_{\mathrm{y}} \cdot \mathrm{x}=0.222\right)$. (C) Shoot length vs. shoot diameter (D, millimeters); model: $\ln \left(\mathrm{L}_{\mathrm{S}}\right)=1.0442+$ $1.2974 \ln (\mathrm{D})\left(R^{2}=0.91 ; \mathrm{s}_{\mathrm{y} \cdot \mathrm{x}}=0.165\right)$. (D) Needle density (DEN, needles per centimeter) vs. shoot length; model: $\ln (\mathrm{DEN})=3.8001-0.3350 \ln \left(\mathrm{L}_{\mathrm{s}}\right)$ $\left(R^{2}=0.43 ; \mathrm{s}_{\mathrm{y} . \mathrm{x}}=0.208\right)$. (E) Average needle dry weight $\left(\mathrm{WT}_{\mathrm{N}}\right.$, milligrams) vs. shoot length; model: $\ln \left(\mathrm{WT} \mathrm{T}_{\mathrm{N}}\right)=1.2236+0.2415 \ln \left(\mathrm{L}_{\mathrm{S}}\right)\left(R^{2}=\right.$ $\left.0.16, \mathrm{~s}_{\mathrm{y} \cdot \mathrm{x}}=0.297\right)$. (F) Average needle dry weight vs. shoot diameter; model: $\ln \left(\mathrm{WT} \mathrm{T}_{\mathrm{N}}\right)=1.3650+0.3936 \ln (\mathrm{D})\left(R^{2}=0.23, \mathrm{~s}_{\mathrm{y} \cdot \mathrm{x}}=0.284\right.$. Basis $=162$ current-year shoots. Each point is the mean for all needles sampled on the shoot. $l n=$ natural logarithm. All models were significant $(P=0.01)$; $S_{y} \cdot x=S E$ of regression. 


\section{SHOOT TRAITS}
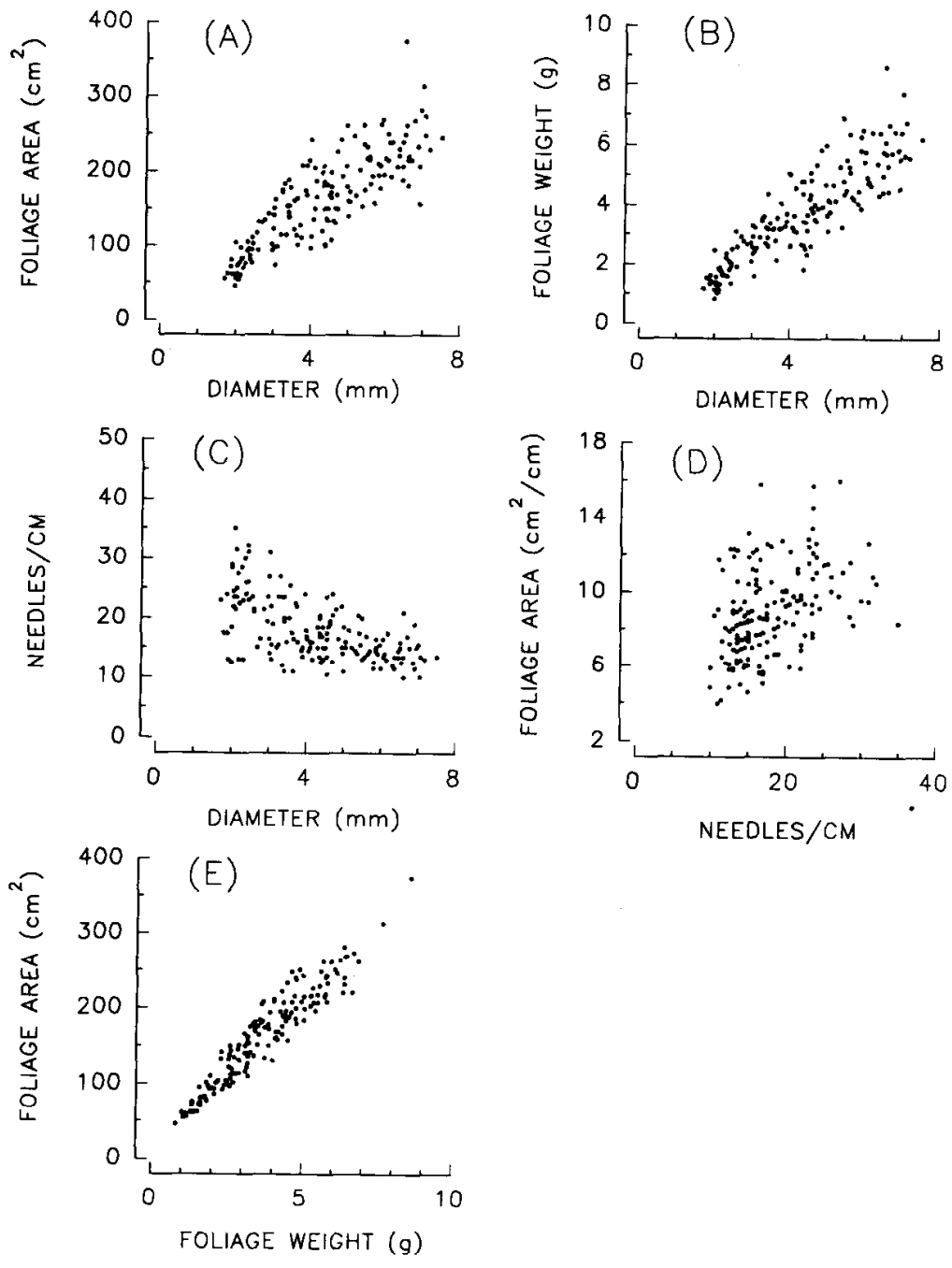

Fig. 7. Relationship between shoot traits of Fraser fir. (A) Total foliage area $\left(A_{F}\right.$ one-sided, square centimeters) vs. diameter (D, millimeters); model: $\ln \left(\mathrm{A}_{\mathrm{F}}\right)=3.6632+0.96621 \mathrm{n}(\mathrm{D})\left(R^{2}=0.76\right.$; $\left.\mathrm{S}_{y, \mathrm{x}}=0.214\right)$. (B) Total foliage dry weight $\left(\mathrm{WT}_{\mathrm{F}}\right.$, grams) vs. diameter; model: $\sqrt{ } \mathrm{W} \mathrm{T}_{\mathrm{F}}=0.452$ $+0.446(\mathrm{D})-0.0232\left(\mathrm{D}^{2}\right)\left(R^{2}=0.79 ; \mathrm{s}_{\mathrm{y} \cdot \mathrm{x}}==0.195\right)$. (C) Needle density (DEN, needles per centimeter) vs. diameter; model: $\mathrm{DEN}=31.4-4.57(\mathrm{D})+0.295\left(\mathrm{D}^{2}\right)\left(R^{2}=0.37 ; \mathrm{s}_{y \times}=4.15\right)$. (D) Foliage area per centimeter of shoot length $\left(\mathrm{A}_{\mathrm{CM}}\right.$, square centimeter per centimeters) vs. needle density; model: $\ln \left(\mathrm{A}_{\mathrm{CM}}\right)=0.8855+0.4478 \ln (\mathrm{DEN})\left(R^{2}=0.20 ; \mathrm{s}_{\mathrm{y} \cdot \mathrm{x}}=0.245\right)$. (E) Total foliage area $\left(\mathrm{A}_{\mathrm{F}}\right)$ vs. total foliage dry weight $\left(\mathrm{WT}_{\mathrm{F}}\right) ;$ model: $\ln \left(\mathrm{A}_{\mathrm{F}}\right)=3.9532+0.8671 \ln \left(\mathrm{WT}_{\mathrm{F}}\right)\left(R^{2}=\right.$ $\left.0.93 ; \mathrm{s}_{y \cdot \mathrm{x}}=0.118\right)$. Basis $=162$ current-year shoots. Each point is a mean for all needles sampled on that shoot. In $=$ natural logirthm. All models were significant $(P=0.01) ; \mathrm{s}_{y \cdot x}=\mathrm{SE}$ of regression.

(Fig. 2E) were more uniform at all positions along the shoot. Specific area (Fig. 2F) increased from an average of $42 \mathrm{~cm}^{2} \cdot \mathrm{g}^{-1}$ at the shoot base to $49 \mathrm{~cm} \cdot \mathrm{g}^{-1}$ at the distal end.

Regardless of the number of needles in the spiral, needle dry weight (Fig. 3A), length (Fig. 3B), and area (Fig. 3C) increased from the adaxial side (top) of the spiral to the abaxial (lower) side. Needle thickness (Fig. 3D) was relatively constant within the spiral, whereas width (Fig. 3E) increased slightly from top to bottom. Specific area (Fig. 3F) was highest in the lower side of the spiral.

Needle length was closely related to needle area (Fig. $4 \mathrm{~A}, R^{2}=0.90$ ) and dry weight (Fig. 4B, $R^{2}=0.58$ ). Long needles tended to be wider than short ones (Fig. $4 \mathrm{C}, R^{2}=$ 0.27 ), and needle density decreased with in- creasing needle length (Fig. $4 \mathrm{D}, R=0.23$ ). Specific area was independent of needle length (data not shown).

Needle area (Fig. 5A, $R^{2}=0.51$ ), dry weight (Fig. $5 \mathrm{~B}, R^{2}=0.62$ ), and thickness (Fig. 5C, $R^{2}=0.22$ ) increased with needle width, but wide needles tended to have a lower specific area than narrow needles (Fig. $\left.5 \mathrm{D}, R^{2}=0.17\right)$. Needle dry weight increased with needle thickness (Fig. 5E, $R^{2}$ $=0.39$ ), whereas specific area decreased (Fig. 5F, $R^{2}=0.26$ ).

Total foliage dry weight (Fig. 6A, $R^{2}=$ 0.72 ), total foliage area (Fig. $6 \mathrm{~B}, R^{2}=0.74$ ), and shoot diameter (Fig. 6C, $R^{2}=0.91$ ) increased with shoot length, but needle density was highest in small shoots (Fig. 6D, $R^{2}=0.43$ ). Average dry weight of individual needles increased slightly with increasing shoot length (Fig. 6E, $R^{2}=0.16$ ) and shoot diameter (Fig. 6F, $R^{2}=0.23$ ), but variability was large, especially in small shoots. The relationship between average needle length and shoot length/diameter was very weak $\left(R^{2}=0.06\right.$ to 0.07 , data not shown); for average needle area, it was only slightly stronger $\left(R^{2}=0.11\right.$ to 0.13 , data not shown).

Foliage area, dry weight, and needle density were related to shoot diameter in the same manner as shoot length (Fig. 7A-7C). Foliage area per centimeter of shoot length increased with increasing needle density (Fig. $7 \mathrm{D}, R^{2}=0.20$ ), and total surface area of foliage was strongly correlated with foliage dry weight (Fig. 7E, $R^{2}=0.93$ ).

The best regression model for estimating dry weight of foliage $\left(\mathrm{W}_{\mathrm{F}}\right.$, in grams) on a shoot Was as follows: $\mathrm{W}_{\mathrm{F}}=-3.77+$ $0.035\left(\mathrm{~L}_{\mathrm{s}}\right)+0.68(\mathrm{D})+0.27\left(\mathrm{WT}_{\mathrm{L}+\mathrm{S}}\right)+$ $0.085(\mathrm{DEN})$, where $\mathrm{L}_{\mathrm{s}}=$ shoot length (centimeters), $\mathrm{D}=$ shoot diameter (millimeters), $\mathrm{WT}_{\mathrm{L}+\mathrm{S}}=$ mean dry weight (milligrams) of the top (smallest) and bottom (largest) needles in a single spiral at the $50 \%$ position (Fig. $1)$, and DEN = needle density per centimeter of shoot length $\left(R^{2}=0.88 ; \mathrm{s}_{\mathrm{y} \cdot \mathrm{x}}=\right.$ $0.551)$. For estimating foliage surface area on a shoot $\left(\mathrm{A}_{\mathrm{F}}\right.$, one-sided, square centimeters), the best model was: $A_{\mathrm{F}}=-224.6+$ $2.38\left(\mathrm{~L}_{\mathrm{s}}\right)+23.75(\mathrm{D})+6.93\left(\mathrm{~L}_{\mathrm{L}+\mathrm{S}}\right)+$ $16.02\left(\mathrm{~W}_{\mathrm{L}+\mathrm{s}}\right)+3.83(\mathrm{DEN})$, where $\mathrm{L}_{\mathrm{L}+\mathrm{s}}$ and $\mathrm{W}_{\mathrm{L}+\mathrm{S}}=$ average length (millimeters) and width (millimeters), respectively, of the top and bottom needles in a single spiral at the $50 \%$ position $\left(R^{2}=0.88 ; s_{y \cdot x}=22.6\right)$.

Specific area (one-sided) on individual current-year shoots was 32 to $60 \mathrm{~cm}^{2} \cdot \mathrm{g}^{-1}$, with an average of $45 \mathrm{~cm}^{2} \cdot \mathrm{g}^{-1}(\mathrm{SE}=0.48)$ (Figs. 2F and 3F). Published values (all-sided) for other Abies spp. range from 82 to 152 $\mathrm{c} \mathrm{m}^{2} \cdot \mathrm{g}^{-1}$ (Gholz et al., 1976; Hadley and Smith, 1990; Tadaki et al., 1970).

Based on foliage weights derived in other studies (Hinesley and Wright, 1989; Weaver and DeSelm, 1973), well-stocked stands of Fraser fir have a one-sided leaf-area index (LAI) of about eight. This value is in the lower range of published values for other Abies spp. (Gholz et al., 1976; Leverenz and Hinckley, 1990; Tadaki et al, 1970). Abies spp. typically have a high LAI, reflecting their capacity to photosynthesize efficiently in shade (Leverenz and Hinckley, 1990).

The stability of foliage area in Fraser fir results from an inverse relationship between needle density and needle length (Fig. 4D) and an inverse relationship between needle density and shoot length (Fig. 6D) or diameter (Fig. 7C). Consequently, total area (Fig. 7D) and weight (data not shown) of foliage per centimeter of shoot is only weakly related to needle density. These mechanisms tend to stabilize photosynthetic potential, as with balsam fir (Piene, 1983) and other conifers (Garrett and Zahner, 1973; Juntilla and Heide, 1981). In addition, the close relationship between shoot diameter/length, total surface area, and dry weight of foliage (Figs. 6 and 7) is consistent with the pipe model theory (Waring et al., 1982) in which a unit weight of foliage is serviced by a specific 
cross-sectional area of sapwood.

The change in needle dimensions within spirals (Fig. 3) as well as among positions along the shoot (Fig. 2) underscores the difficulty in determining average needle dimensions on a particular shoot. The largest needles on a shoot were halfway between the proximal and distal ends (Fig. 2) and always on the low (abaxial) side of the spiral, regardless of location along the shoot (Fig. 3).

Although location of a shoot in the crown affects morphology and orientation of foliage (Fig. 1), we did not examine foliage attributes in relation to this factor. Shoots were sampled throughout the crown, and from trees with contrasting needle morphology and density. The objective was not to examine variation in foliage attributes within trees or populations, it was simply to develop a regression model to estimate foliage area using variables such as shoot length, shoot diameter, and mean needle dry weight and/or surface area. If the dimensions of a shoot and an appropriate needle sample are known, one can accurately estimate foliage area and weight with no additional information [note: when logarithmic regressions are back-transformed, correction factors should be included to compensate for bias (Baskerville, 1972; Snowden, 1991)].

These models likely will have practical applications in studies involving light interception, transpiration, and photosynthesis. Changes in needle length, weight, and area are also useful indices of growth response in nutrition studies (Czapowskyj et al., 1980; Smith et al., 1981; Timmer et al., 1977). Such models will also be useful in genetic studies seeking to identify trees with a high
LAI, specific needle area, or high photosynthetic potential.

\section{Literature Cited}

Bailian, L., J.B. Jett and R.J. Weir. 1988. A preliminary study of geographic variation in Fraser fir seedlings. Southern J. Applied For. 12:128132.

Baskerville, G.L. 1972. Use of logarithmic regression in the estimation of plant biomass. Can. J. For. Res. 2:49-53.

Chandler, J.W. and J.E. Dale. 1990. Needle growth in sitka spruce (Picea sitchemis): Effects of nutrient deficiency and needle position within shoots. Tree Physiol. 6:41-56.

Czapowslryji, M.M., L.O. Safford, and R.D. Briggs. 1980. Foliar nutrient status of young red spruce and balsam fir in a fertilized stand. U.S. Dept. Agr. Forest Ser., Northeastern Forest Expt. Sta. Res. Paper NE-467.

Drew, A.P. and S.W. Running. 1973. Comparison of two techniques for measuring surface area of conifer needles. Forest Sci. 21:231-233.

Garrett, P.W. and R. Zahner. 1973. Fascicle density and needle growth responses of red pine to water supply over two seasons. Ecology 54:1328-1334.

Gholz, H.L., F.K. Fitz, and R.H. Waring. 1976. Leaf area differences associated with old-growth forest communities in the western Oregon Cascades. Can. J. For. Res. 6:49-57.

Hadley, J.L. and W.K. Smith. 1990. Influence of leaf surface wax and leaf area to water content ratio on cuticular transpiration in western conifers USA. Can. J. For. Res. 20:1306-1311.

Hinesley, L.E. and R.D. Wright. 1989. Biomass and nutrient accumulation in Fraser-fir Christmas trees. HortScience 24:280-282.

Juntilla, O. and O.M. Heide. 1981. Shoot and needle growth in Pinus sylvestris as related to temperature in Northern Fennoscandia. Forest Sci. 27:423-430.
Leverenz, J.W. and T.M. Hinckley. 1990. Shoot structure, leaf area index and productivity of evergreen conifer stands. Tree Physiol. 6:135149.

Loomis, R.M., R.E. Phares, and J.S. Crosby. 1966. Estimating foliage and branchwood quantities in shortleaf pine. Forest Sci. 12:30-39.

Piene, H. 1983. Nondestructive estimation of foliar biomass in balsam fir. Can. J. For. Res. 13:672-677.

Robinson, J.F. and E. Thor. 1969. Natural variation in Abies of the southern Appalachians. Forest Sci. 15:238-245.

SAS Institute. 1989. SAS/STAT user's guide. version 6, 4th ed. SAS Institute, Gary, N.C.

Smith, R.B., R.H. Waring, and D.A. Perry. 1981. Interpreting foliar analyses from Douglas-fir as weight per unit leaf area. Can. J. For. Res. 11:593-598

Snowden, P. 1991. A ratio estimator for bias correction in logarithmic regressions. Can. J. For. Res. 21:720-724.

Tadaki, Y., K. Hatiya, K. Tochiaki, H. Miyauchi, and U. Matsuda. 1970. Studies on the production structure of forest. XVI. Primary productivity of Abies veitchii forests in the subalpine zone of Mt. Fugi. p. 1-22. Ringyo Shikenjo, Tokyo.

Timmer, V.R., E.L. Stone, and D.G. Embree. 1977. Growth response of young balsam fir fertilized with nitrogen, phosphorous, potassium and lime. Can. J. For. Res. 7:441-446.

Waring, R.H., P.E. Schroeder, and R. Gren. 1982. Application of pipe model theory to predict canopy leaf area. Can. J. For. Res. 12 556-560.

Weaver, G.T. and H.R. DeSelm. 1973. Biomass distribution patterns in adjacent conifers and deciduous ecosystems. p. 415-427. In: Intl. Union Forest Res. Organizations biomass studies. College of Life Sci. and Agr., Univ. of Maine, Orono. 